\title{
Benign Febrile Myoclonus in Childhood
}

\author{
J.M. Dooley and J.D. Hayden
}

\begin{abstract}
Background: Myoclonus is often associated with progressive myoclonic epilepsy or neurodegenerative conditions. Febrile myoclonus is a benign phenomenon, which has only been reported previously in one child. Methods: The clinical features of three children with fever-induced myoclonus are described. Results: Fever-induced myoclonus is characterized by frequent myoclonus, which resolves with resolution of the fever in otherwise healthy children. Conclusions: Recognition of fever-induced myoclonus as a benign phenomenon may prevent unnecessary investigations and interventions.
\end{abstract}

RÉSUMÉ: Myoclonus fébrile bénin de l'enfance. Introduction: Le myoclonus est souvent associé à l'épilepsie myoclonique progressive ou à des maladies neurodégénératives. Le myoclonus fébrile est un phénomène bénin dont un seul cas a été rapporté chez l'enfant. Méthodes: Nous décrivons les caractéristiques cliniques de trois enfants qui ont présenté un myoclonus induit par une hyperthermie. Résultats: Le myoclonus induit par l'hyperthermie est caractérisé par un myoclonus fréquent qui disparaît quand l'hyperthermie rentre dans l'ordre chez des enfants en bonne santé. Conclusions: Le fait de reconnaître le myoclonus induit par l'hyperthermie comme un phénomène bénin peut éviter des investigations et des interventions inutiles.

Can. J. Neurol. Sci. 2004; 31: 504-505

Myoclonus is often an ominous harbinger of underlying neurological disease. Although most often encountered in the context of infantile spasms and the Lennox-Gastaut syndrome, ${ }^{1}$ the differential diagnosis of myoclonus includes neurodegenerative disorders and some more benign phenomena. Fever-induced myoclonus or febrile myoclonus is poorly recognized and has only been reported in one previous patient. ${ }^{2}$ We report three children with febrile myoclonus, all of whom had a benign outcome.

\section{Patient 1}

A 23-month-old female presented to the Emergency Room with a 24-hour history of fever, lethargy and brief generalized myoclonic jerks, which were slightly more prominent on the left. The myoclonus occurred every five minutes and was present during both wakefulness and sleep. She was developmentally normal and had no past history of neurological illness.

The family history was negative for movement disorders and seizures but her mother did have a history of syncope.

On examination she had a fever of $39^{\circ} \mathrm{C}$ and was lethargic. Neurological examination was normal and antipyretic medications dramatically reduced the frequency of the myoclonus. The myoclonus disappeared with resolution of the fever. On follow-up 18 months after the presenting episode she continued to have occasional myoclonus with fever but was otherwise neurologically and developmentally normal.

\section{Patient 2}

The 30-month old nephew of the emergency room nurse attending Patient 1 had a history of febrile myoclonus while under her care at 18 months of age. The episode was described as a sudden onset of generalized myoclonus in association with a fever of $39.8^{\circ} \mathrm{C}$ secondary to bilateral otitis media. Intermittent myoclonus persisted for several hours until the fever was controlled.

His past history was unremarkable and he was neurologically and developmentally normal. Despite further episodes of fever he has not had a recurrence of myoclonus during the subsequent 12 months.

The family history was negative for movement disorders and seizures, including febrile seizures, but his maternal aunt had a history of a single syncope related seizure.

\section{Patient 3}

This patient was the 16-year old daughter of a pediatrician. At 18-months of age she had an episode of generalized myoclonus in association with a fever of $40^{\circ} \mathrm{C}$ and erythema infectiosum. The myoclonus resolved with control of the fever and she has never had any subsequent abnormal movements or other neurological problems.

Her family history was also negative for seizures and movement disorders but was positive for syncope in a sibling.

From the Division of Pediatric Neurology, Dalhousie University and IWK Health Centre, Halifax, Nova Scotia, Canada.

ReCeived SePtember 12, 2003. ACCEPTEd infinalform JANUARy 5, 2004 Reprint requests to: J.M. Dooley, Division of Pediatric Neurology, IWK Health Centre, 5850 University Avenue, Halifax, Nova Scotia, Canada B3J 3G9 


\section{Discussion}

Myoclonus may be physiological, essential, epileptic or symptomatic of underlying neurological disease. ${ }^{3}$ Physiologic myoclonus occurs in normal children in specific circumstances such as while falling asleep. Essential myoclonus usually begins in the first or second decade and has a nonprogressive course. It is usually inherited as an autosomal dominant trait but may be sporadic. $^{4,5}$

Children presenting to the emergency room with myoclonus usually have epilepsy. ${ }^{1}$ Benign myoclonus of infancy may appear similar to infantile spasms but is characterized by a normal EEG and nonprogressive course. ${ }^{6}$ Progressive myoclonic epilepsies are characterized by a combination of myoclonus, seizures and progressive neurologic deterioration. In children, progressive myoclonic epilepsy may be due to Lafora body disease, neuronal ceroid lipofuscinosis (Batten disease), Unverricht-Lundborg disease, myoclonic epilepsy with ragged red fibers, or sialidosis (a lysosomal storage disorder). Myoclonus may also accompany neurodegenerative disorders and may be induced by drugs, such as the newer anti-epileptic drugs lamotrigine ${ }^{7}$ and gabapentin. ${ }^{8}$ In adolescents, early morning myoclonus usually suggests a diagnosis of juvenile myoclonic epilepsy.

Fever associated myoclonus is less well-recognized although myoclonic seizures have been reported in hyperthermic rats ${ }^{9}$ and myoclonus has been reported in humans with encephalitis ${ }^{10,11}$ and with specific infections. ${ }^{12,13}$ Children with severe myoclonic epilepsy (Dravet syndrome) frequently experience an aggravation of their seizures, including myoclonus with fever. Oguni et $\mathrm{al}^{14}$ have reviewed the association between temperature elevation and seizures. Studies of Japanese hot baths, in which the whole body is immersed in a bath-tub filled with water at 39$42^{\circ} \mathrm{C}$ for 5-10 minutes, help to differentiate the effects of fever, the underlying infection or para-infectious processes. ${ }^{14}$ Clearly children with severe myoclonic epilepsy of infancy can have seizures precipitated by fever.

Nonspecific febrile myoclonus has only been reported in one previous patient although many pediatric neurologists reported that they had seen similar patients. ${ }^{2}$ Our patients had feverprecipitated myoclonus, which resolved with fever control. The follow-up of 16 years in patient 3 indicates that this phenomenon is benign.

Rajakumar and Bodensteiner ${ }^{2}$ suggested a possible association between febrile myoclonus and febrile seizures but our patients had neither a personal nor family history of febrile seizures. The pathophysiology of febrile myoclonus remains unclear. None of our patients underwent EEG and we are, therefore, unable to determine if the myoclonus is cortical in origin. An association with syncope is possible as myoclonus frequently occurs with syncope ${ }^{15,16}$ and all of our patients had a family history of syncope.

The prevalence of febrile myoclonus is unknown, although a survey of pediatric neurologists ${ }^{2}$ and our informal questioning of emergency room pediatricians suggest that it is a relatively common phenomenon. Nevertheless children who present with myoclonus are often subjected to extensive investigations because of the association between myoclonus and progressive epilepsy syndromes.

It is important to recognize that children can have benign febrile myoclonus or other benign fever-related movement disorders, ${ }^{17,18}$ although such conditions are poorly-recognized and are seldom reported in the literature.

\section{REFERENCES}

1. Aicardi J. Myoclonic epilepsies of infancy and childhood. In: Fahn S, Marsden CD, Van Woert M, (Eds). Advances in Neurology: Myoclonus. New York: Raven 1986;43:11-31.

2. Rajakumar K, Bodensteiner JB. Febrile myoclonus: a survey of pediatric neurologists. Clin Pediatr 1996;35:331-332.

3. Fenichel GM. Clinical Pediatric Neurology: A Signs and Symptoms Approach. Philadelphia: WB Saunders, 2001:293-294.

4. Daube JR, Peters HL. Hereditary essential myoclonus. Arch Neurol 1966;15:587-594.

5. Bressman S, Fahn S. Essential myoclonus. In: Fahn S, Marsden CD, Van Woert M, (Eds). Advances in Neurology: Myoclonus. New York: Raven 1986;43:287-294.

6. Lombroso CT, Fejerman N. Benign myoclonus of early infancy. Ann Neurol 1977;1:38-43.

7. Janszky J, Rasonyi G, Halsz P, et al. Disabling erratic myoclonus during lamotrigine therapy with high serum-level-report of 2 cases. Clin Neuropharmacol 2000;23:86-89.

8. Asconape J, Diedrich A, Dellabadia J. Myoclonus associated with the use of gabapentin. Epilepsia 2000; 4: 479-481.

9. Morimoto T, Yoshimatsu M, Nagao H, Matsuda H. Three types of hyperthermic seizures in rats. Brain Dev 1992;14:53-57.

10. Lam SK, Chua KB. Nipah virus encephalitis outbreak in Malaysia. Clin Infect Dis 2002;34 (Suppl 2):48-51.

11. Hommel D, Heraud JM, Hulin A, Talarmin A. Association of Tonate virus (subtype IIIB of the Venezuelan equine encephalitis complex) with encephalitis in a human. Clin Infect Dis 2000;30:188-190.

12. McMinn P, Stratov I, Nagarajan L, Davis S. Neurological manifestations of enterovirus 71 infection in children during an outbreak of hand, foot and mouth disease in Western Australia. Clin Infect Dis 2001;32:236-242.

13. Maegaki Y, Akaboshi S, Inagak M, Takeshita K. Unilateral involuntary movement associated with streptococcal infection: neurophysiological investigation. Neuropediatrics 2000;31:7074.

14. Oguni H, Hayashi K, Awaya Y, Kukuyama Y, Osawa M. Severe myoclonic epilepsy in infants - a review based on the Tokyo Women's Medical University series of 84 cases. Brain Dev 2001;23:736-748.

15. Kempster PA, Balla JI. A clinical study of convulsive syncope. Clin Exp Neurol 1986;22:53-55.

16. Morrell MJ. Differential diagnosis of seizures. Neurol Clin 1993;11:737-754.

17. Dooley J, Gordon K, Stewart W. Autosomal dominant fever induced dystonia. Can J Neurol Sci 2001;28 (Suppl 2):S70.

18. Bodensteiner J. Stress-induced movement disorders. Clin Pediatr 2001;40:53-54. 